\title{
New year, new faces and new copy
}

\author{
European Journal of Human Genetics (2005) 13, 1. doi:10.1038/sj.ejhg.5201346
}

At the start of the 13th volume, there are several improvements and developments to report.

First, from this issue onwards the readers will find a new category, 'News and Commentary', with items of relevance to the broad field of Human Genetics, presented in a format accessible to a wide readership, much like the 'News and Views' found in Nature. These contributions, typically less than 1000 words, are picked from the recent literature (or other newsworthy events) and can be identified by the editors as well as the readership. Suggestions - of topics as well as authors - are welcomed at ejhg@lumc.nl.

In the past year, the EJHG has seen a further steady rise in submissions, resulting in the editorial office now receiving typically 50 manuscripts per month. As a consequence, we have agreed with our publisher, Nature Publishing Group, to expand the size of the journal significantly: from 1070 to 1270 pages per volume. The first effect of this you may already have noticed by picking up this issue with no less than 130 pages of copy. Despite this increase in size, to fit the accepted manuscripts in our page budget, we will have to become yet more demanding of the quality, general scope and potential impact of the manuscripts submitted. This is part of the ongoing maturation of the EJHG and we are confident that this will result in a further increase in our Impact Factor score. Other indications of the EJHG's rising impact are the $35 \%$ increases of both Table-ofContents recipients and page views of our website, as well as the significant increase of our subscriber basis in the US, all in the last year.

To deal with the increased submissions, we also have expanded our panel of Section Editors. We welcome three new Section Editors: Markus Perola (Helsinki), who will replace Leena Peltonen, current President of the ESHG, as Section Editor of Genetic Epidemiology. Furthermore,
Nicholas Katsanis (Baltimore, US) and Phil Beales (London, UK) will strengthen our review section as specific Reviews Editors, also taking the Practical Genetics series under their wings. This will take some setting up so you will find out more on this later in the spring. In total, therefore, we have enlisted the expertise of four new scientists this year, as Mark Daly (Cambridge, US) also joined us in 2004 as Section Editor for Statistical Genetics and Genetic Epidemiology.

In the current issue, you will find the typical mix of clinical, molecular and cytogenetics you have become used to from the EJHG, as well as the first News and Commentaries, dealing with the diagnosis of Fragile $\mathrm{X}$ associated Tremor-Ataxia Syndrome (FXTAS) ${ }^{1}$ and the role of Acetylcholine transport in Duchenne Muscular Dystrophy. ${ }^{2}$ Finally, a special mention is deserved by the very comprehensive and thorough literature review by Karnebeek et $a l^{3}$ of diagnostic investigations in mental retardation patients, with extensive supplementary information available online. For the early and online readers of this issue, this is a hefty read worth at least a part of the Christmas holiday.

GertJan B van Ommen Editor-in-Chief

\section{References}

1 Jaquemont S: Screening for FXTAS. Eur J Hum Genet 2005; 13: 2-3.

2 Ségalat L, Anderson JE: Duchenne Muscular Dystrophy: Stalled at the Junction? Eur J Hum Genet 2005; 13: 4-5.

3 van Karnebeek CDM, Jansweijer MCE, Leenders ACE et al: Diagnostic investigation in individuals with mental retardation: a systematic literature review of their usefulness. Eur J Hum Genet 2005; 13: 6-25. 